\title{
Gastrointestinal Safety of Aspirin for a High-Dose, Multiple-Day Treatment Regimen: A Meta-Analysis of Three Randomized Controlled Trials
}

\author{
Samantha Forder ${ }^{1} \cdot$ Michael Voelker ${ }^{2} \cdot$ Angel Lanas $^{3}$
}

Published online: 23 July 2016

(c) The Author(s) 2016. This article is published with open access at Springerlink.com

\begin{abstract}
Background and Aim Aspirin is a commonly used overthe-counter (OTC) agent for the symptomatic treatment of acute pain, fever, or the common cold, but data regarding safety in this context are limited. In order to characterize the safety of aspirin beyond single-dose or long-term use data, we conducted a meta-analysis of multiple-dose, multiple-day studies of OTC aspirin at a label-approved dosage.

Methods We conducted a meta-analysis of individual patient data from three Bayer-sponsored studies. The metaanalysis was performed in 2015; the individual studies were conducted between 2008 and 2012 and were of a randomized, parallel-group, placebo-controlled design. Patients received a minimum dosage of aspirin of $2000 \mathrm{mg} /$ day over at least 3 days. The endpoints were patient-reported adverse events (AEs) with an emphasis on the system organ class gastrointestinal system. Event incidences were estimated and an analysis of the odds ratios (ORs) and risk differences (RDs) of aspirin versus placebo were performed.

Results Of the 819 patients included, 433 were treated with aspirin and 386 were treated with placebo. The majority of patients $(85.7 \%)$ received a median dose of aspirin of $3000 \mathrm{mg} /$ day for 3 days. The incidence of the overall AEs was low and rates were comparable between the aspirin $(10.9 \%)$ and placebo $(12.4 \%)$ groups [OR: $0.86(95 \%$
\end{abstract}

Michael Voelker

michael.voelker@bayer.com

1 Bayer, Whippany, NJ, USA

2 Bayer, Leverkusen, Germany

3 IIS Aragón, CIBERehd, University of Zaragoza, Zaragoza, Spain confidence interval [CI] 0.56, 1.34); RD: -1.49 (95\% CI $-6.01,3.03)]$. Gastrointestinal AEs were more common in subjects treated with aspirin $(7.4 \%)$ than with placebo $(5.4 \%)$, and although this difference did not reach statistical significance, a trend towards increased risk was observed with aspirin use [OR: 1.41 (95\% CI 0.78, 2.54); RD: 2.00 (95\% CI -1.35, 5.35)]. Nausea, upper abdominal pain, dyspepsia, and diarrhea were the most frequently reported gastrointestinal AEs. There were no reports of serious gastrointestinal complications such as bleeding, perforation, or ulceration.

Conclusions The multiple-dose regimen of aspirin used for several days according to the OTC label is well-tolerated by otherwise healthy non-elderly subjects for short-term and symptomatic treatment of pain, fever, and the common cold. There were no reports of serious gastrointestinal complications in either of the groups.

\section{Key Points}

The overall incidence of adverse events (AEs) was low with multiple-dose aspirin used for several days $(10.9 \%)$, with rates comparable with those of placebo (12.4\%).

A trend towards an increased risk of gastrointestinal AEs was observed with aspirin relative to placebo, with incidences of 7.4 and $5.4 \%$, respectively.

There were no reports of serious gastrointestinal complications such as bleeding, perforation, or ulceration. 


\section{Background}

Aspirin (acetylsalicylic acid) is one of the most commonly used over-the-counter (OTC) drugs in the world, and is used for acute self-treatment of symptoms of pain, fever, or the common cold [1-3]. The recommended OTC dose for these indications is generally $500-1000 \mathrm{mg}$ repeated at 4to 8-h intervals, and is not to exceed 3000 or $4000 \mathrm{mg} / \mathrm{day}$, depending on country regulations. Treatment in this setting is typically short-term (mostly 3-5 days), with the exact duration of therapy dependent on local country regulations and the indication.

At OTC analgesic doses, aspirin behaves as a traditional non-selective non-steroidal anti-inflammatory drug (NSAID), in that it inhibits both cyclo-oxygenase (COX)-1 and COX-2 enzymes [4]. This non-selective COX inhibition is tied to many of the adverse events (AEs) commonly associated with this class of medication. Serious gastrointestinal complications such as perforations, ulcers, or bleeding have rarely been reported with short-term or single-dose studies using OTC doses of aspirin [5, 6]. However, more minor gastrointestinal complaints (i.e., dyspepsia) are also of concern, as their occurrence often leads to avoidance of appropriate treatment by the patient.

Data characterizing the safety profile of OTC aspirin when used within recommended dose and short-term duration parameters are quite limited. Observational studies may not distinguish between short- and long-term OTC use, may not specify the exact doses administered, and in some cases OTC data are not captured at all. This discrepancy is important when considering differences regarding the indication, duration of therapy, and population taking prescription or long-term OTC drugs versus short-term OTC use. As a result, the increased risk of ulcers, bleeding, perforations, or other serious gastrointestinal complications associated with long-term NSAID use may not accurately represent the magnitude of risk when these drugs are used as directed in the OTC setting.

This notion is supported by limited data, existing largely in the form of single-dose and very short-term use studies [5-8]. In performing the current meta-analysis we sought to characterize the safety and tolerability of multiple high OTC doses of aspirin, used over several days for the symptomatic treatment of acute pain, fever, or the common cold.

\section{Methods}

We conducted a descriptive, integrated safety meta-analysis utilizing individual patient data obtained from Bayer AG (Leverkusen, Germany)-sponsored studies conducted to May 2015, in which aspirin was evaluated in a clinical trial setting and adequate documentation of $\mathrm{AE}$ reporting was available. Studies qualified for analysis if they met the following criteria: (1) contained a treatment arm with patients receiving aspirin monotherapy at doses $\geq 2000 \mathrm{mg} /$ day for $\geq 3$ days; and (2) were conducted in a randomized, placebocontrolled, parallel-group design. Of 87 clinical trials identified within the Bayer study data pool and conducted between 1987 and 2012, three satisfied all requirements and were included in the safety analysis. All three studies were designed with active and placebo comparators, and two contained an aspirin plus pseudoephedrine arm. However, only the aspirin monotherapy and placebo arms of each study were evaluated. Details of the aspirin treatment regimens administered in each study are shown in Table 1. In general, daily doses of aspirin were between 1000 and $3000 \mathrm{mg}$ for a duration of 3-5 days.

The endpoints of interest were patient-reported AEs. AEs of interest were chosen based on previous knowledge of the safety profile of aspirin and NSAID class-specific AEs. Medical Dictionary for Regulatory Activities $\left(\right.$ MedDRA $\left.^{\circledR}\right)$ codes (version 18.0) were used to identify these events within the data pool according to either standardized MedDRA $^{\circledR}$ queries (SMQs) or selected MedDRA $^{\circledR}$ preferred terms (PTs), high-level terms (HLTs), high-level group terms (HLGTs), or system organ classes (SOCs). Of the AEs, the gastrointestinal SOC and its related PTs, the combination of the gastrointestinal disorders heartburn, nausea, vomiting, and abdominal pain was of major interest for this analysis because their occurrence often leads to avoidance of appropriate treatment by the patient. Another area of interest was the serious events gastrointestinal hemorrhage, gastrointestinal ulceration, and gastrointestinal perforation.

Data management and statistical evaluation were performed using the $S A S^{\circledR}$ software package version 9.3 (SAS Institute, Cary, NC, USA). The target SAS $^{\circledR}$ database structure was based on agreement between Bayer AG (Leverkusen, Germany) and the M.A.R.C.O. Institute for Clinical Research and Statistics (Düsseldorf, Germany). Bayer provided SAS ${ }^{\circledR}$ datasets for the studies, which were transformed into the target database structure using $\mathrm{SAS}^{\circledR}$ modification programs. Information derived from the clinical study reports and listings (i.e., study title, design, blinding, randomization, dosing, AE reporting) was integrated into the target database. Quality control checks were in place at each data management step. Checks included double data entry and standard validation of statistical programs and data entry including review by a second programmer. The statistical analysis was exploratory in nature and based on available data.

Estimated incidence rates were presented for overall AEs, SOCs, and PTs, and events within each of these categories were categorized by intensity (mild, moderate, 
Table 1 Characteristics of the studies included in the meta-analysis

\begin{tabular}{|c|c|c|c|}
\hline Characteristic & Study 1 & Study 2 & Study 3 \\
\hline Study design & $\begin{array}{l}\text { Randomized, double-blind, } \\
\text { placebo-controlled, parallel }\end{array}$ & $\begin{array}{l}\text { Randomized, double-blind, } \\
\text { placebo-controlled, parallel }\end{array}$ & $\begin{array}{l}\text { Randomized, double-blind, placebo-controlled, } \\
\text { parallel }\end{array}$ \\
\hline Clinical phase & III & III & III \\
\hline $\begin{array}{l}\text { Number of } \\
\text { centers }\end{array}$ & 68 & 12 & 1 \\
\hline Countries & $\begin{array}{l}\text { Italy, Poland, Slovakia, and } \\
\text { USA }\end{array}$ & Germany and UK & UK \\
\hline Indication & Acute sore throat & Acute lower back pain & Acute sore throat and/or headache \\
\hline Dosage & $\begin{array}{l}1000 \mathrm{mg} \text { tid for } 3 \text { days; daily } \\
\text { dose } 3000 \mathrm{mg}\end{array}$ & $\begin{array}{l}1000 \mathrm{mg} \text { tid prn for } 5 \text { days; daily } \\
\text { dose } 3000 \mathrm{mg} \text { maximum }\end{array}$ & $\begin{array}{l}1000 \mathrm{mg} \text { bid or tid on day } 1 \text { and } 1000 \mathrm{mg} \text { tid on } \\
\text { days } 2 \text { and 3; daily dose } 3000 \mathrm{mg} \text { maximum }\end{array}$ \\
\hline $\begin{array}{l}\text { Treatment arms } \\
\text { (safety set) }\end{array}$ & $\begin{array}{l}\text { Aspirin }(n=250) \\
\text { Placebo }(n=262) \\
\text { Aspirin/pseudoephedrine } \\
\quad(n=253) \\
\text { Pseudoephedrine }(n=251)\end{array}$ & $\begin{array}{l}\text { Aspirin }(n=112) \\
\text { Placebo }(n=116) \\
\text { Ibuprofen }(n=109)\end{array}$ & $\begin{array}{l}\text { Aspirin }(n=240) \\
\text { Placebo }(n=121) \\
\text { Aspirin/pseudoephedrine }(n=235) \\
\text { Pseudoephedrine }(n=237)\end{array}$ \\
\hline $\begin{array}{l}\text { Patients included } \\
\text { in the analysis }\end{array}$ & $\begin{array}{l}\text { Aspirin }(n=149) \\
\text { Placebo }(n=196)\end{array}$ & $\begin{array}{l}\text { Aspirin }(n=54) \\
\text { Placebo }(n=69)\end{array}$ & $\begin{array}{l}\text { Aspirin }(n=230) \\
\text { Placebo }(n=121)\end{array}$ \\
\hline Subject sex & $\begin{array}{l}\text { Male: } 44 \% \\
\text { Female: } 56 \%\end{array}$ & $\begin{array}{l}\text { Male: } 53 \% \\
\text { Female: } 47 \%\end{array}$ & $\begin{array}{l}\text { Male: } 29 \% \\
\text { Female: } 71 \%\end{array}$ \\
\hline \multicolumn{4}{|l|}{ Age (years) } \\
\hline Mean (range) & $36.6(18-65)$ & $46.0(17-81)$ & $20.1(18-39)$ \\
\hline Median & 35.0 & 46.0 & 20.0 \\
\hline
\end{tabular}

bid twice daily, prn as needed, tid three times daily

severe) for both the aspirin and placebo groups. An analysis of odds ratios (ORs) and risk differences (RDs) of aspirin versus placebo was performed.

\section{Results}

The data pool used for the meta-analysis consisted of a total of 819 subjects; 433 subjects received aspirin, 386 received placebo. All studies were multiple-dose studies evaluating the efficacy of aspirin versus placebo in the short-term treatment of sore throat, headache, or lower back pain. An overview of the individual study characteristics is provided in Table 1 .

Patient-reported AEs of the individuals included in the studies were analyzed. The current study compared the safety of aspirin monotherapy versus placebo and, therefore, although the individual studies were each designed with active and placebo comparators, only the aspirin monotherapy and placebo arms were included in the metaanalysis. Subject demographics for both meta-analysis treatment groups are described in further detail in Table 2. With the exception of age and sex, baseline characteristics were generally comparable between the groups. The majority of patients in the aspirin group received a median dose of $3000 \mathrm{mg} / \mathrm{day}$ for 3 days $(n=372 ; 86 \%)$. The remaining patients $(n=62 ; 14 \%)$ received 2500 or $3000 \mathrm{mg} /$ day for 4-6 days. The duration of aspirin exposure was greatest for the low back pain study (up to 6 days) compared with 3 or 4 days for sore throat and headache. The overall median total exposure to aspirin per patient was $8000 \mathrm{mg}$.

Overall, the AE incidences were comparable between the aspirin $(10.9 \%)$ and placebo groups $(12.4 \%)$ [OR: 0.86 (95\% confidence interval [CI] 0.56, 1.34); RD: -1.49 (95\% CI $-6.01,3.03)]$. Reported events were mostly mild to moderate in nature (Table 3). One serious AE occurred in the aspirin group (non-cardiac chest pain), but this was determined to be unrelated to study drug. One patient, also in the aspirin group, discontinued treatment due to a skin rash that developed following 3 days of aspirin therapy and which was therefore classified as an adverse drug reaction.

Gastrointestinal AEs were more common in subjects treated with aspirin $(7.4 \%)$ than placebo $(5.4 \%)$. Though this difference did not meet statistical significance, a trend towards higher risk was observed with aspirin use compared with placebo [OR: 1.41 (95\% CI 0.78, 2.54); RD: $2.00(95 \% \mathrm{CI}-1.35,5.35)]$. The gastrointestinal PTs 
Table 2 Subject demographics of the study population

\begin{tabular}{|c|c|c|c|}
\hline Demographic & Aspirin $(N=433)$ & Placebo $(N=386)$ & Total $(N=819)$ \\
\hline \multicolumn{4}{|l|}{$\operatorname{Sex}[n(\%)]$} \\
\hline Men & $151(34.9)$ & $167(43.3)$ & $318(38.8)$ \\
\hline Women & $282(65.1)$ & $219(56.7)$ & $501(61.2)$ \\
\hline \multicolumn{4}{|l|}{$\operatorname{Race}[n(\%)]$} \\
\hline Caucasian & $423(97.7)$ & $375(97.2)$ & $798(97.4)$ \\
\hline Black & $1(0.2)$ & $2(0.5)$ & $3(0.4)$ \\
\hline Asian & $6(1.4)$ & $5(1.3)$ & $11(1.3)$ \\
\hline Other & $3(0.7)$ & $4(1.0)$ & $7(0.9)$ \\
\hline \multicolumn{4}{|l|}{ Age (years) } \\
\hline Mean (SD) & $29.1(13.16)$ & $33.0(14.16)$ & $30.9(13.76)$ \\
\hline Range & $18-81$ & $17-77$ & $17-81$ \\
\hline Median & 22.0 & 28.5 & 25.0 \\
\hline \multicolumn{4}{|l|}{ Height $(\mathrm{cm})$} \\
\hline Mean (SD) & $169.6(9.48)$ & $170.6(9.24)$ & $170.1(9.37)$ \\
\hline Range & $147-203$ & $152-201$ & $147-203$ \\
\hline \multicolumn{4}{|l|}{ Weight (kg) } \\
\hline Mean (SD) & 69.94 (13.57) & 71.06 (13.94) & $70.47(13.75)$ \\
\hline Range & $42.0-121.4$ & $45.0-120.0$ & $42.0-121.4$ \\
\hline \multicolumn{4}{|l|}{ BMI $\left(\mathrm{kg} / \mathrm{m}^{2}\right)$} \\
\hline Mean (SD) & $24.23(3.806)$ & $24.29(3.530)$ & $24.26(3.676)$ \\
\hline Range & $16.8-45.1$ & $16.5-36.2$ & $16.5-45.1$ \\
\hline
\end{tabular}

$B M I$ body mass index, $S D$ standard deviation

Table 3 Incidences, odds ratios, and risk differences for adverse events

\begin{tabular}{|c|c|c|c|c|}
\hline \multirow[t]{2}{*}{ Event } & \multicolumn{2}{|c|}{ Response/treated } & \multirow{2}{*}{$\begin{array}{l}\text { Odds ratio (95\% } \\
\text { CI) }\end{array}$} & \multirow{2}{*}{$\begin{array}{l}\text { Risk difference (95\% } \\
\text { CI) }\end{array}$} \\
\hline & $\begin{array}{l}\text { Aspirin } \\
{[N(\%)]}\end{array}$ & $\begin{array}{l}\text { Placebo } \\
{[N(\%)]}\end{array}$ & & \\
\hline Adverse events & $47 / 433(10.9)$ & 48/386 (12.4) & $0.86(0.56,1.34)$ & $-1.49(-6.01,3.03)$ \\
\hline Mild intensity & $18(4.2)$ & $24(6.2)$ & n.c. & n.c. \\
\hline Moderate intensity & $19(4.4)$ & $16(4.1)$ & n.c. & n.c. \\
\hline Severe intensity & $10(2.3)$ & $8(2.1)$ & n.c. & n.c. \\
\hline Gastrointestinal adverse events & $32 / 433(7.4)$ & $21 / 386(5.4)$ & $1.41(0.78,2.54)$ & $2.00(-1.35,5.35)$ \\
\hline Dyspepsia & $5 / 433(1.2)$ & $1 / 386(0.3)$ & $5.14(0.60,44.25)$ & $1.01(-0.17,2.19)$ \\
\hline $\begin{array}{l}\text { Combined heartburn, nausea, vomiting, and abdominal } \\
\text { pain }\end{array}$ & $27 / 433(6.2)$ & $17 / 386(4.4)$ & $1.43(0.76,2.73)$ & $1.78(-1.33,4.89)$ \\
\hline Headache & $6 / 433(1.4)$ & $13 / 386(3.4)$ & $0.45(0.17,1.23)$ & $-1.74(-3.88,0.41)$ \\
\hline Dizziness & $4 / 433(0.9)$ & $4 / 386(1.0)$ & $1.04(0.26,4.20)$ & $0.04(-1.40,1.49)$ \\
\hline Tinnitus & $3 / 203(1.5)$ & $0 / 265(0.0)$ & $36.10(0.10,13,705)$ & $1.48(-0.18,3.13)$ \\
\hline Abdominal pain & $3 / 379(0.8)$ & 2/317 (0.6) & $1.71(0.27,10.82)$ & $0.38(-0.89,1.64)$ \\
\hline
\end{tabular}

CI confidence interval; n.c. not calculated

heartburn, nausea, vomiting, and abdominal pain are of major importance for the tolerability of aspirin [5, 6]. The incidence of their combination was higher in the aspirin group than in the placebo group (6.2 vs. $4.4 \%$ ), but differences did not reach statistical significance. However, there was again a trend towards an increased risk for aspirin [OR: 1.43 (95\% CI 0.76, 2.73); RD: 1.78 (95\% CI $-1.33,4.89)]$. The same higher incidence in the aspirin group was observed for the PT dyspepsia (aspirin $1.2 \%$, placebo $0.3 \%$ ), but it had a high OR (5.14) with a very 
broad $95 \%$ CI $(0.60,44.25)$, indicating little precision due to a limited number of events. Incidences and ORs calculated for headache, dizziness, tinnitus, and abdominal pain showed no additional risk associated with aspirin compared with placebo (Table 3). There were no reports of serious gastrointestinal complications such as perforations, ulcers, and bleeding, as was the case with impaired hearing ability, mental confusion, cerebral hemorrhage, and hypersensitivity reactions.

\section{Discussion}

The findings from the current individual patient data metaanalysis appear to support the safety and tolerability of the use of multiple high-dose treatment with aspirin in the selfmedication setting for the acute treatment of pain, fever, or the common cold in an otherwise healthy and young population. Aspirin use was not associated with a significant increase in the risk of overall or gastrointestinal-specific AEs. In fact, ORs and RDs for the comparison of aspirin and placebo were not statistically significant for any of the safety endpoints. Gastrointestinal AEs occurred at a low rate overall, and, importantly, no cases of serious gastrointestinal complications (i.e., perforation, ulceration, or bleeding) were reported. However, the generalizability of these findings to a broader population is inappropriate as the data used for this meta-analysis were sourced from a limited pool of qualifying Bayer-sponsored studies, which comprised healthy, younger adult subjects at low risk of gastrointestinal events. This could have contributed to the low incidence of gastrointestinal AEs observed in both treatment groups.

This multiple-dose meta-analysis enhances the existing safety profile of OTC aspirin used for non-cardiac indications, as the large majority of existing data are derived from very short-term, mostly single-dose studies. It must be emphasized, however, that though the doses and durations of aspirin treatment included in this study extend beyond single-dose administration, they still reflect short-term treatment in the OTC setting. Therefore, conclusions drawn from these data are not valid in the context of long-term use, or use that lies outside of the treatment algorithms outlined in these studies.

The results of the current analysis are generally in agreement with findings from four previous meta-analyses and one randomized controlled clinical trial examining the safety of acute OTC aspirin use. Meta-analyses by Lanas et al. [5], Edwards et al. [7], and Steiner and Voelker [8] consisted mostly of single-dose data, while the current analysis, Baron et al. [6], and the PAIN [Paracetamol, Aspirin and Ibuprofen New tolerability] study [9] examined higher OTC doses used for a longer duration
(3-10 days). In order to bring the current data into perspective, Table 4 shows the incidences, ORs, RDs, and relative risks of overall and gastrointestinal AEs.

Among the meta-analyses, the incidence of aspirin versus placebo AEs is consistently in the range of 10-15\%, and the AEs reported in the current analysis were comparable between the aspirin and placebo groups (10.9 vs. $12.4 \%$ ). Lanas et al. [5] observed a similar pattern (15.2 vs. $15.5 \%$ ), although these AE rates appear to be higher than those seen in our study. This could be due, in part, to the substantially larger population in the Lanas et al. [5] analysis. The Edwards et al. [7] and Steiner and Voelker [8] analyses reported AE incidences within a similar range (13 vs. $11 \%$ and 14.9 vs. $11.1 \%$, respectively) to those seen in Lanas et al. [5] and the current study.

The incidence of gastrointestinal AEs is generally in the range of 6-10\% for aspirin (including the PAIN study) and 4-9 \% for placebo, showing a substantial overlap of the two ranges. The incidence of gastrointestinal AEs was higher in the aspirin than in the placebo group (7.4 vs. $5.4 \%$ ) in the current analysis, a pattern also seen in the study by Lanas et al. [5] (9.9 vs. $9.0 \%)$, although the increase in risk was significant in that study (OR 1.3; $95 \%$ CI 1.1, 1.5). The Baron et al. [6] meta-analysis also observed a higher incidence of overall gastrointestinal risk with aspirin use than with placebo, but reported no serious AEs.

The AE of interest, dyspepsia, was associated with an OR of 5.14 in the current study. However, there is a very wide CI associated with this estimate $(0.6,44)$, suggesting a substantial level of variability in the data due to the low number of cases (sparse data scenario), but also a trend towards significance due to the large right shift of the CI. Yet, upon examining the data from the Lanas et al. [5] analysis, it becomes apparent that this finding in our study should not be disregarded: Lanas et al. [5] found a significantly higher risk of dyspepsia in patients taking aspirin. Again, the difference in population size could have contributed to the discrepancy in the results observed for these two studies.

Taken together, these results suggest that the safety and tolerability seen with short-term OTC aspirin (used according to the directions on the label) extends to multiple-day use (not to exceed 3-10 days depending on local country regulations and indication) in a population with low gastrointestinal risk. It must be noted, however, that this observation may not apply to higher-risk patients such as the elderly or those with a history of ulcers, and is only representative of an acute clinical scenario appropriate for self-treatment. No previously unknown risks, which would change the overall benefitrisk ratio of aspirin for pain and fever, have been 
Table 4 Comparison of studies investigating the safety and tolerability of aspirin

\begin{tabular}{|c|c|c|c|c|c|c|}
\hline & $\begin{array}{l}\text { Current meta- } \\
\text { analysis }\end{array}$ & $\begin{array}{l}\text { Lanas et al. [5] } \\
\text { meta-analysis }\end{array}$ & $\begin{array}{l}\text { Edwards et al. } \\
\text { [7] meta- } \\
\text { analysis }\end{array}$ & $\begin{array}{l}\text { Steiner and Voelker } \\
{[8] \text { meta-analysis }}\end{array}$ & $\begin{array}{l}\text { Baron et al. [6] } \\
\text { meta-analysis }\end{array}$ & $\begin{array}{l}\text { PAIN study RCT } \\
\text { [9] }\end{array}$ \\
\hline Year & 2015 & 2011 & 1999 & 2009 & 2013 & 1999 \\
\hline $\begin{array}{l}\text { Number of } \\
\text { studies/patients }\end{array}$ & $3 / 819$ & $67 / 13,222$ & $72 / 6550$ & $9 / 2852$ & $78 / 19,829$ & 8633 patients \\
\hline $\begin{array}{l}\text { Patient } \\
\text { population } \\
\text { included }\end{array}$ & $\begin{array}{l}\text { Patients with } \\
\text { symptomatic upper } \\
\text { respiratory tract } \\
\text { infection or acute } \\
\text { lower back pain }\end{array}$ & $\begin{array}{l}\text { Patients with } \\
\text { pain, fever, } \\
\text { or common } \\
\text { cold }\end{array}$ & $\begin{array}{l}\text { Patients with } \\
\text { post- } \\
\text { operative } \\
\text { pain }\end{array}$ & $\begin{array}{l}\text { Patients with acute } \\
\text { migraine attacks, } \\
\text { episodic tension- } \\
\text { type headache, } \\
\text { and dental pain }\end{array}$ & $\begin{array}{l}\text { Patients on ASA } \\
\text { who experienced a } \\
\text { GI event }\end{array}$ & $\begin{array}{l}\text { Patients with } \\
\text { common mild to } \\
\text { moderate pain }\end{array}$ \\
\hline Treatments & $\begin{array}{l}\text { Daily ASA dose of } \\
2000 \mathrm{mg} \text { taken for } \\
\text { a minimum } \\
\text { duration of } 3 \text { days } \\
\text { and up to } 6 \text { days }\end{array}$ & $\begin{array}{l}\text { Mostly single } \\
\text { ASA doses of } \\
\geq 325 \mathrm{mg} / \text { day }\end{array}$ & $\begin{array}{l}\text { Single-dose } \\
\text { ASA } \\
600 / 650 \\
1000, \text { or } \\
1200 \mathrm{mg}\end{array}$ & $\begin{array}{l}\text { Single doses of ASA } \\
1000 \mathrm{mg}\end{array}$ & $\begin{array}{l}\text { ASA dose between } \\
325 \text { and } \\
4000 \mathrm{mg} / \text { day with } \\
\text { a treatment } \\
\text { duration of up to } \\
10 \text { days }\end{array}$ & $\begin{array}{l}\text { ASA up to } 3 \mathrm{~g} / \text { day, } \\
\text { PAR up to } \\
3 \mathrm{~g} / \text { day, or IBU } \\
\text { up to } 1.2 \mathrm{~g} / \text { day } \\
\text { for up to } 7 \text { days }\end{array}$ \\
\hline Safety endpoint & Patient-reported AEs & $\begin{array}{l}\text { Patient- } \\
\text { reported AEs }\end{array}$ & $\begin{array}{l}\text { Patient- } \\
\text { reported } \\
\text { AEs }\end{array}$ & $\begin{array}{l}\text { Patient-reported } \\
\text { AEs }\end{array}$ & $\begin{array}{l}\text { Patient-reported } \\
\text { AEs }\end{array}$ & $\begin{array}{l}\text { Patient-reported } \\
\text { AEs }\end{array}$ \\
\hline \multicolumn{7}{|l|}{ Results [95 \% CI] } \\
\hline All AEs & $\begin{array}{l}\text { ASA } 10.9 \% \\
\text { Placebo } 12.4 \% \\
\text { OR } 0.86[0.56,1.34] \\
\text { RD }-1.49[-6.01, \\
3.03]\end{array}$ & $\begin{array}{l}\text { ASA } 15.2 \% \\
\text { Placebo } \\
15.5 \% \\
\text { OR } 1.1[0.96, \\
1.2] \\
\text { RD 1.0 [-0.5, } \\
\text { 2.5] }\end{array}$ & $\begin{array}{l}\text { ASA all doses } \\
12.0 \% \\
\text { Placebo } \\
10.0 \% \\
\text { RR } 1.3[0.9, \\
1.5] \\
\text { ASA 600/650 } \\
\text { mg } 13.0 \% \\
\text { Placebo } \\
11.0 \% \\
\text { RR } 1.2[1.03, \\
1.4]\end{array}$ & $\begin{array}{l}\text { ASA } 14.9 \% \\
\text { Placebo } 11.1 \% \\
\text { RR } 1.3[1.1,1.6]\end{array}$ & Not available & $\begin{array}{l}\text { ASA } 18.5 \% \\
\text { IBU } 13.4 \% \\
\text { PAR } 13.8 \%\end{array}$ \\
\hline GI AEs & $\begin{array}{l}\text { ASA } 7.4 \% \\
\text { Placebo } 5.4 \% \\
\text { OR } 1.41[0.78,2.54] \\
\text { RD 2.00 [-1.35, } \\
5.35]\end{array}$ & $\begin{array}{l}\text { ASA } 9.9 \% \\
\text { Placebo } 9.0 \% \\
\text { OR 1.3 [1.1, } \\
\text { 1.5] } \\
\text { RD 2.1 [0.9, } \\
3.3]\end{array}$ & $\begin{array}{l}\text { ASA } \\
600 / 650 \mathrm{mg} \\
3.7 \% \\
\text { Placebo } 1.1 \% \\
\text { RR 2.5 [1.2, } \\
5.1]\end{array}$ & $\begin{array}{l}\text { ASA } 5.9 \% \\
\text { Placebo } 3.5 \% \\
\text { RR } 1.7[1.2,2.4]\end{array}$ & $\begin{array}{l}\text { ASA } 9.4 \% \\
\text { Placebo } 4.2 \% \\
\text { OR } 2.12[0.95,4.76]\end{array}$ & $\begin{array}{l}\text { ASA } 7.1 \% \\
\text { IBU } 4.0 \% \\
\text { PAR } 5.3 \%\end{array}$ \\
\hline
\end{tabular}

$\overline{A E s \text { adverse events, } A S A \text { aspirin, } C I \text { confidence interval, } G I \text { gastrointestinal, } I B U \text { ibuprofen, } O R \text { odds ratio, } P A R \text { paracetamol, } R C T \text { randomized }}$ controlled trial, $R D$ risk difference, $R R$ relative risk

detected in the current or previous analyses and studies. Furthermore, serious AEs such as perforations, ulcers, and bleeding have not been observed in these clinical investigations.

The frequency of AEs was quite low in the current analysis and the meta-analyses discussed here. This may in part be due to the population studied, as subjects were typically young and otherwise healthy. This probably does not mirror the patient populations from several observational studies that have suggested that aspirin taken for pain, fever, or the common cold is associated with an increased risk of major gastrointestinal complications, similar to other non-selective NSAIDs [10-12]. A recent large population-based study found that those on prescription NSAIDs were generally older, more frequently overweight, and had more co-morbidities than their OTC NSAID-using counterparts [3]. While there is a wellknown association between long-term NSAID use, the above-mentioned risk factors, and an increased likelihood of developing serious gastrointestinal complications, caution must be exercised in drawing generalized conclusions from data obtained specifically from OTC or prescriptionstrength NSAID use, as these data may not be applicable to a broader or disparate population. 
ORs and RDs for the comparison of aspirin and placebo were not statistically significant for any of the safety endpoints of interest. However, interpretation of these results must be accompanied by a thorough inspection of the limitations of the analysis. First, the analysis population was young and generally healthy. Furthermore, the total sample size is limited. A low number of events may have impaired the sensitivity of the analysis to detect a difference between aspirin and placebo. In this situation, a lack of statistical significance should not be considered synonymous with the conclusion that aspirin does not increase the risk of gastrointestinal AEs, particularly for endpoints for which other studies have shown a trend for such an association. The studies included in the analysis did not prohibit the use of gastroprotective agents, though concomitant medications were documented and subjects were generally healthy.

\section{Conclusions}

This analysis shows that OTC aspirin taken at doses of 2500-3000 mg/day over 3-6 days is well-tolerated when taken as directed for the treatment of acute pain, fever, and the common cold. Though the incidence of gastrointestinal AEs was elevated in aspirin users compared with placebo users, the risk of these AEs was not statistically significantly different, and there were no reports of serious gastrointestinal complications in either of the groups. However, it is critical that the results of this study should be interpreted within the full context of the limited sample size. Therefore, firm conclusions cannot be drawn based on these data alone.

\section{Compliance with Ethical Standards}

This study was funded by Bayer AG, Leverkusen, Germany, and performed by M.A.R.C.O., Dusseldorf, Germany, an independent institute for clinical research and statistics. During the development of this manuscript, Samantha Forder was completing a post-doctoral fellowship through a partnership between Bayer and Rutgers University, New Brunswick, NJ, USA. Michael Voelker is a full-time employee of Bayer AG. Angel Lanas is supported by the University of Zaragoza, Zaragoza, Spain. Dr. Lanas has received honoraria for participation in advisory boards and for a previous related study from Bayer. All authors contributed sufficiently to the development, review, and revision of this manuscript.
Open Access This article is distributed under the terms of the Creative Commons Attribution-NonCommercial 4.0 International License (http://creativecommons.org/licenses/by-nc/4.0/), which permits any noncommercial use, distribution, and reproduction in any medium, provided you give appropriate credit to the original author(s) and the source, provide a link to the Creative Commons license, and indicate if changes were made.

\section{References}

1. Curhan GC, Bullock AJ, Hankinson SE, et al. Frequency of use of acetaminophen, nonsteroidal anti-inflammatory drugs, and aspirin in US women. Pharmacoepidemiol Drug Saf. 2002;11:687-93.

2. Kaufman DW, Kelly JP, Rosenberg L, et al. Recent patterns of medication use in the ambulatory adult population of the United States: the Slone survey. JAMA. 2002;287:337-44.

3. Koffeman AR, Valkhoff VE, Celik S, et al. High-risk use of overthe-counter non-steroidal anti-inflammatory drugs: a population based cross-sectional study. Br J Gen Pract. 2014;64:e191-8.

4. Vane JR. Inhibition of prostaglandin synthesis as a mechanism of action for aspirin-like drugs. Nat New Biol. 1971;231:232-5.

5. Lanas A, McCarthy D, Voelker M, et al. Short-term acetylsalicylic acid (aspirin) use for pain, fever, or colds - gastrointestinal adverse effects: a meta-analysis of randomized clinical trials. Drugs R D. 2011;11:277-88.

6. Baron JA, Senn S, Voelker M, et al. Gastrointestinal adverse effects of short-term aspirin use: a meta-analysis of published randomized controlled trials. Drugs R D. 2013;13:9-16.

7. Edwards JE, Oldman AD, Smith LA, et al. Oral aspirin in postoperative pain: a quantitative systematic review. Pain. 1999;81:289-97.

8. Steiner T, Voelker M. Gastrointestinal tolerability of aspirin and the choice of over-the-counter analgesia for shortlasting acute pain. J Clin Pharm Ther. 2009;34:177-86.

9. Moore N, Van Ganse E, Le Parc JM, et al. The PAIN study: paracetamol, aspirin and ibuprofen new tolerability study. A large-scale, randomised clinical trial comparing the tolerability of aspirin, ibuprofen and paracetamol for short-term analgesia. Clin Drug Invest. 1999;18:89-98.

10. Rostom A, Muir K, Dubé C, et al. Gastrointestinal safety of cyclooxygenase- 2 inhibitors: a Cochrane Collaboration systematic review. Clin Gastroenterol Hepatol. 2007;5:818-28.

11. Lanas A, Garcia-Rodriguez LA, Arroyo MT, et al. Risk of upper gastrointestinal ulcer bleeding associated with selective cyclooxygenase- 2 inhibitors, traditional nonaspirin non-steroidal antiinflammatory drugs, aspirin and combinations. Gut. 2006;55:1731-8.

12. Lanas A, Bajador E, Serrano P, et al. Nitrovasodilators, low-dose aspirin, other nonsteroidal anti-inflammatory drugs, and the risk of upper gastrointestinal bleeding. N Engl J Med. 2000;343:834-9. 